\title{
Title: Working with Law Students to Develop Legal Literacy materials
}

\author{
Authors: Dr Dawn Watkins and Dr Maribel Canto-Lopez, School of Law, \\ University of Leicester
}

\section{Acknowledgements}

The authors wish to thank the children (then in years 3 and 4) and staff at St Peter's Primary Academy, Market Bosworth, for partnering with us in this work. Particular thanks to head teacher Ralph Wood for generously providing help and expertise at every stage of the project. We express our thanks also to Tony Thorpe, Don Rowe, Alison Davies and Elizabeth Cornish for lending their support to this project, and to the Higher Education Academy for funding it within its teaching development grant scheme. We thank the anonymous reviewers for their helpful comments on an earlier draft of this paper and last but certainly not least we wish to thank all of the University of Leicester Law students who participated in the project with such enthusiasm and generosity of spirit.

\footnotetext{
Abstract

This paper sets out the findings of a teaching development project undertaken with undergraduate law students at the University of Leicester (UOL) in 2013-14, funded by the Higher Education Academy (HEA). In the course of this project, students were actively involved in the design, development and delivery of five interactive workshops for primary school children; each built around a particular theme and each designed to help develop an aspect of the children's legal literacy. The aims were to assess the impact on the learning experience of student participants; to assess whether it may be possible to incorporate this form of activity within the undergraduate curriculum and to assess whether it may be possible to create a sustainable model for use in the future, with new groups of students and a wider number of schools. The most positive
} 
outcomes of the project relate to the students' self-reporting of the development of transferable skills and their reported increase in self-confidence, as a result of being involved in the project. The role of group work in the development of transferable skills is also evident. By far the weakest area was the demonstration and development of legal research skills. The authors reflect on these findings, and comment on some of the unforeseen benefits and challenges of the project, before drawing conclusions as to its future viability.

Key words: legal literacy, school, public legal education, students as partners, transferable skills

\section{Setting the Scene: the Context of the Project}

The broad context for this work is the involvement of law students in the field of public legal education ('PLE') described as 'a range of activities and initiatives that aim to improve people's lives and empower communities. ${ }^{1}$ Interest in PLE has increased in recent years ${ }^{2}$ and its significance as part of a wider strategy for increasing public access to legal advice and support is recognised, particularly as access to legal aid has diminished. ${ }^{3}$ The project was initially linked also with the development of Street Law within the Law School, but was unusual in that it sought to engage with primary schoolaged children, rather than older children, as is more usual with Street Law activities. ${ }^{4}$

\footnotetext{
${ }^{1}$ PLENET, Public legal education - Improving lives, empowering communities, p.1 Available at http://www.lawforlife.org.uk/wp-content/uploads/Public-Legal-Education-Improving-lives-empoweringcommunities.pdf (accessed 24 March 2015)

${ }^{2}$ Nigel J. Balmer, Alexy Buck, Ash Patel, Catrina Denvir, Pascoe Pleasence, Knowledge, capability and the experience of rights problems, (Plenet, 2010) at 1.2. Available at http://www.lawforlife.org.uk/wpcontent/uploads/2010/05/knowledge-capability-and-the-experience-of-rights-problems-lsrc-may-2010255.pdf (accessed 24 March 2015)

${ }^{3}$ Report of the Low Commission Tackling The Advice Deficit - A strategy for access to advice and legal support on social welfare law in England and Wales (Legal Action Group, 2014) at 5.9. Available at <http://www.lowcommission.org.uk/dyn/1389221772932/Low-Commission-Report-FINALVERSION.pdf $>$ (accessed 24 March 2015)

${ }^{4}$ Street Law was founded in 1972 in Georgetown University Law Center. See <http://www.streetlaw.org/en/about/who_we are> (accessed 24 March 2015) .Street Law is a non-profit organization that creates classroom and community programs that teach people about law, democracy, and
} 
Also foundational to the project was an awareness that citizenship is a compulsory element of the curriculum in schools at key stages 3 and 4 , but not in key stage $2 .^{5}$

The project built on a pilot study that took place in May 2013, where 13 law students from the UOL (mostly Street Law volunteers, but not exclusively so) engaged approximately 60 primary school children in a mock trial of Jack (from Jack and the Beanstalk). Subsequently, the students talked to the children in groups, to find out what they knew about law and where it comes from. Based on positive student feedback gathered after this pilot study, a successful application was made to HEA's teaching development grant scheme, responding to three of the HEA's substantive thematic call areas; education for sustainable development, employability and students as partners. ${ }^{6}$

Prior to the pilot study in May 2013, ethical clearance was obtained from the UOL's Research Ethics office in respect of this project. In line with British Educational Research Association's (BERA) guidelines and the UOL's ethical research policy, the following steps were taken to ensure that all participants were treated fairly, equally and with respect: Students were provided with a project information sheet, detailing the aims and objectives of the project. They were invited to sign an informed consent form, which made clear that they were free to withdraw from the project at any time, for any or no reason. Students were asked to provide permission for their comments, as set out in their reflective journals, blogs and feedback emails, to be analysed and reproduced anonymously (in full or in part) in the research outputs. Students were free to withdraw

human rights worldwide. A number of UK University law schools have developed similar programmes in recent years. See LawWorks, Street Law Handbook (LawWorks, 2006)

${ }^{5}$ See D Rowe and T Thorpe, Your Rights and Responsibilities (Evans Brothers Ltd., 2002); D Rowe, 1992, 'Law-related education: an overview', in J. Lynch, C. Modgil \& S. Modgil (eds) Cultural Diversity and the Schools, Vol 4: Human Rights, Education and Global Responsibilities, ,(Falmer Press, 1992); D Rowe, 'The citizen and the law', in N. Baglin \& E. Baglin Jones (eds) Education for Citizenship: cross-curricular themes and perspectives, (Kogan Page, 1992).

${ }^{6}$ The other thematic areas are flexible learning, internationalisation, retention and success, reward and recognition and online learning. See 〈https://www.heacademy.ac.uk/workstreams-research/themes > (accessed 14 March 2015). 
such consent at any time up to publication. Students' reflective blogs were posted in a dedicated Blackboard site, which is accessible only by the project leaders and project participants. Students also gave consent for materials created in the course of the project to be made freely available for future use and development, both within and outside of the UOL. Via their school, children were provided with details of the project, and signed consents were obtained from the children's parent/carer and from the children themselves prior to their participating. ${ }^{7}$

Following consultation with colleagues in the Career Development Service and the Schools and Colleges Service, it was decided that the most appropriate location for the project was within the existing Leicester Award for Employability scheme ('Leicester Award'). Within this scheme, students complete a number of generic tasks designed to develop employability skills, but choose also to pursue one of a range of extra-curricular activities or 'Leicester Award Experiences' offered. ${ }^{8}$ One advantage of offering 'Developing legal literacy with children in key stage 2' as one of these experiences was that it gave students the incentive of obtaining a University-accredited award at the end of the programme, in recognition of the considerable time and effort involved.

It was envisaged that the project could accommodate 25 students; who were selected via the Leicester Award application process. Because of the nature of the project work, it was made available to law students only. We received 47 applications and selected 32 students from this pool, ${ }^{9}$ to allow for no-shows and withdrawals. This proved to be an

\footnotetext{
${ }^{7}$ This is in line with the BERA Guidelines (2011) that state at para. 16: "The Association requires researchers to comply with Articles 3 and 12 of the United Nations Convention on the Rights of the Child. Article 3 requires that in all actions concerning children, the best interests of the child must be the primary consideration. Article 12 requires that children who are capable of forming their own views should be granted the right to express their views freely in all matters affecting them, commensurate with their age and maturity. Children should therefore be facilitated to give fully informed consent."

${ }^{8}$ Details of the scheme can be found at http://www2.le.ac.uk/offices/careers-new/exp/la (accessed 24 March 2015). The Leicester Award is a personal skills development programme which recognises and adds value to the activities students at the UOL engage with outside of their degree. The award helps them to reflect upon the skills they are developing, communicate their achievements, and investigate their desired career pathway. It is open only to students in years 2 or 3 of their studies.

${ }^{9}$ The selection criteria looked at evidence of previous experience of working with children and general suitability to the project based on their application.
} 
accurate prediction, as two students withdrew permanently from the project before the school visits took place. And by the end of the project activities a further 5 students had withdrawn for reasons such as illness and/or pressure of work, meaning that 25 completed all aspects of the project.

\section{Project Overview}

The diagram (figure 1) below outlines the core units of the Leicester Award. The initial skills audit caused students to reflect on areas that they wished to develop in the course of the award, and provided the base line for their future reflections concerning selfdevelopment. These consisted of two 500 word reflective blogs at key stages in the project; after the planning activities in semester 1 and at the end of the project in semester 2. This level of self-reflection is not currently developed in other aspects of the undergraduate law curriculum, so it was a new experience for most students. ${ }^{10}$ The impact on the learning experience of student participants was assessed solely by reference to these reflective blogs, which were written by students in light of the issues identified by them in the skills audit. Aspects of the Unit 3 activities were designed by us to coincide with the project aims and activities. Students each made a 5 minute presentation to the children, when the children visited the University campus at the end of the project, and the submission of group materials formed the final assignment task.

Figure 1

\footnotetext{
${ }^{10}$ Because of this, the Leicester Award team provided to students a Reflective Writing Guide that encourages students to outline the skills that they improved through the project and to think about the impact of the experience on their future employability. Leicester Award for Employability Skills 2013-14; Reflective Writing Guide, p.2 (unpublished)
} 


\section{Leicester Award Core Unit}

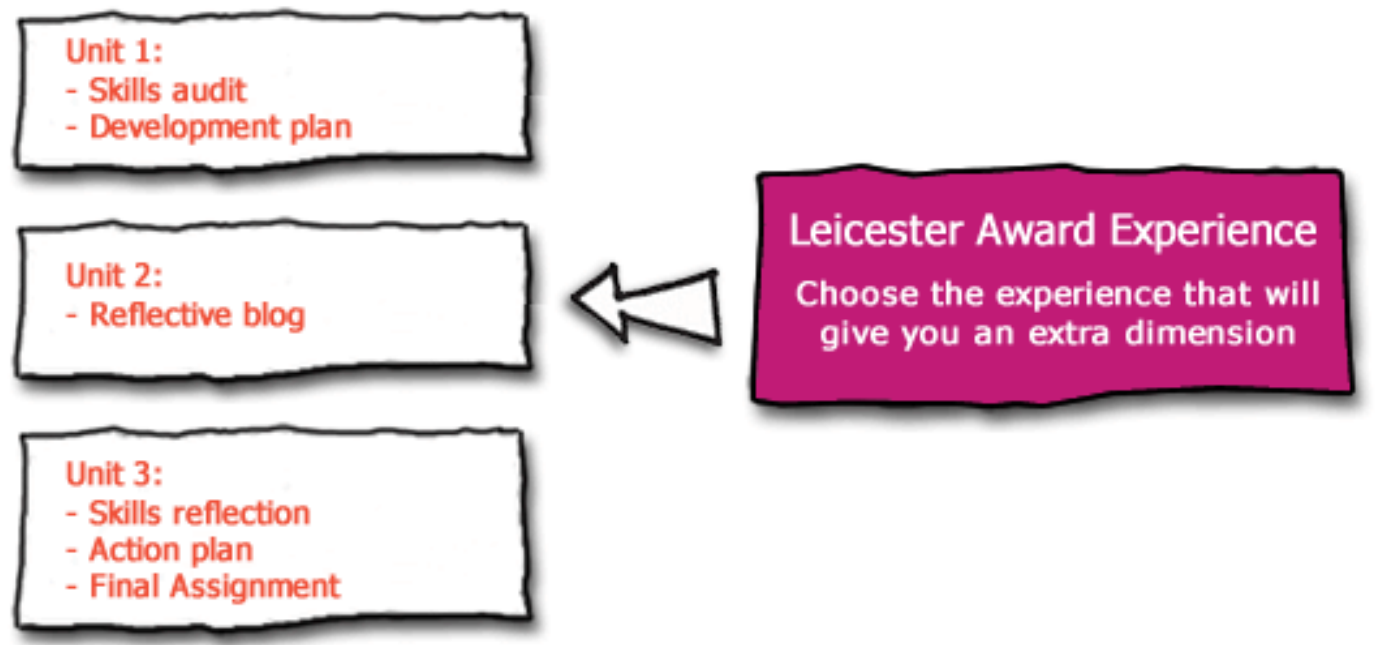

'Developing legal literacy' represented the 'Leicester Award Experience' aspect of the award and the work was separated into two distinct phases. In Semester 1 the students attended two workshops, one full-day and one half-day, to encourage them to think about what 'legal literacy' means for younger children, and to engage them in planning and developing five separate workshops (each lasting one hour) for school. Aspects of these workshops were facilitated variously by Ralph Wood the school's head teacher (himself a UOL Law graduate), by two citizenship specialists Don Rowe and Tony Thorpe, and by Alison Davies, a professional storyteller. ${ }^{11}$ In the course of the first workshop, students were asked to put forward ideas for topics that would be suitable and useful for discussing in school and these were narrowed down to five topics by means of an open discussion between students and the workshop facilitators. ${ }^{12}$ The topics agreed upon were Animal Rights, Human (and Children's) Rights, the Duty of Care, Defamation

\footnotetext{
${ }^{11}$ Tony Thorpe is editor of the Young Citizen's Passport, Your Guide to the Law in England and Wales $16^{\text {th }}$ Ed. (Hodder, 2013). Don Rowe is a former director of the Citizenship Foundation. In this role he co-edited 'You, Me, Us! Social and Moral Responsibility for Primary Schools (published by the Citizenship Foundation in 1994). Alison Davies is author of Storytelling in the Classroom, (Sage, 2007). She was involved previously in a narrative research project involving undergraduate law students at UOL. See D Watkins 'The Role of Narratives in Legal Education' (2011) Vol. 32, 2 Liverpool Law Review, 113

${ }^{12}$ The following topics were suggested by students initially: Human rights and civil liberties, including freedom of speech; the English legal system and law-making; the aims of the law; the duty of care; contract law; defamation, libel and slander; assault and battery; Un Convention on the Rights of the Child; Animal rights; Are laws right or wrong? and International law.
} 
and Criminal Responsibility. Students then organized themselves into groups, according to their preferred area of interest. The second workshop gave students an opportunity to develop their ideas again with expert support, after which time they were expected to prepare and rehearse in their own time, without supervision. Early in Semester 2, students attended a child safeguarding seminar presented by the UOL's safeguarding officer. They then visited the school in their groups; presenting their workshop twice, once to children in year 4 and then again to children in year 5 .

Students conducted their workshops in a variety of ways. ${ }^{13}$ Role plays featured in all of the sessions; some with students presenting to the children, as a basis for subsequent discussion. Others involved the children more actively in role plays, to consolidate the children's understanding of material that had been delivered earlier in the session. The theme of Harry Potter ${ }^{14}$ was adopted by the human rights group as a means of engaging the children with the session and, more practically, as a way of sorting children into 'houses' or groups for activities. ${ }^{15}$ The mock trial of Goldilocks provided the basis for the criminal responsibility session. A number of groups prepared quiz activities that were designed to check the children's understanding of the material at the end of the session, but often found that there was insufficient time to present these within the hour made available for the session. Once all of the school visits had taken place, the children from years 4 and 5 visited the UOL for a morning and assisted in the assessment of the student presentations. Formal assessment was carried out by the member of academic staff, and informal feedback was obtained from student peers and from the children, using specially-prepared feedback forms ${ }^{16}$ Following the student presentations, the visiting children took a guided tour of the campus, attended an

\footnotetext{
${ }^{13}$ Materials created by the students are openly available at www2.le.ac.uk/departments/law/research/developing-legal-literacy

${ }^{14}$ Harry Potter is a series of seven fantasy novels written by the British author J. K. Rowling. The series chronicles the adventures of a young wizard: Harry Potter. The books have been made into an eight-part film series and Harry Potter-themed areas have been created at several theme parks.

${ }^{15}$ In Harry Potter, the first year students of the Wizard School are sorted magically thanks to a 'Sorting Hat' that determines to which of the four school Houses each new student is to be assigned.

${ }^{16}$ Also available with the project materials on the website.
} 
interactive lecture, and listened to a story before being presented with certificates to acknowledge their important role in the project.

\section{Assessing the project}

The project aims were to assess the impact on the learning experience of student participants; to assess whether it may be possible to incorporate this form of activity within the undergraduate curriculum and to assess whether it may be possible to create a sustainable model for use in the future, with new groups of students and a wider number of schools. Of course, the first of these aims strongly influences the findings of second and third since it calls for a qualitative assessment of the project's value to students. Or in other words, the practical challenges of incorporating such activities into the curriculum and/or developing the project are important, but the more pertinent question is, 'is it worth it' from the students' perspective?

As stated earlier, reflective blogs that students submitted in the course of the project provided the data from which the impact on the learning experience of the students was assessed. The authors drew on Krippendorf's content analysis ${ }^{17}$ approach when analysing this data. The content analysis method openly acknowledges and incorporates the significance of context, both in terms of the manner in which the data was gathered, and the way in which it is analysed subsequently. Krippendorf refutes the idea of text possessing objective or "reader-independent" ${ }^{18}$ meanings that can be "'found," "identified," [or] "described"19 and proposes instead that "context is always constructed by someone...no matter how hard they try to objectify it." ${ }^{20}$ On this basis, researchers who adopt Krippendorf's method openly analyse data in light of their predispositions to it. Accordingly, the forthcoming discussion sets out the inferences or

\footnotetext{
${ }^{17}$ K Krippendorff, Content Analysis (Sage, $3{ }^{\text {rd }}$ Ed, 2013)

${ }^{18}$ ibid, p.28

19 ibid.

${ }^{20}$ ibid, p.29
} 
readings that we have drawn from the data, in light of our broader experiences of planning and leading the project.

Although content analysts tend not to lay claim to objectivity in their research, they do conduct data analysis in a systematic way, that seeks to make "replicable and valid inferences from texts (or other meaningful matter) to the contexts of their use." ${ }^{21}$ The analysis of data from this project focused primarily on "identifying patterns that have a high degree of commonality" ${ }^{22}$ by adopting a simple frequency method. ${ }^{23}$ Though it cannot be assumed that levels of frequency correlate with levels of value (and vice versa) $)^{24}$ it is suggested that the context in which the student blogs had been written, together with their reflective properties, made such an assumption credible here. The blogs formed part of the students' assessment for the Leicester Award scheme. On guidance provided to the students within this scheme, indicators for the highest mark range included the need to demonstrate: 'how they are using the experience to develop themselves'; 'goes into detail about a particular skill they have learnt' and 'for full marks, some reference to the future and what they will try next should have been made'. ${ }^{25}$ Whereas this study adopts a broad view of the 'impact on the learning experience' as incorporating academic, vocational, emotional and social factors, there is an inevitably strong focus on employability skills in the Leicester Award scheme and it is acknowledged that this will influence the data.

\section{The development of transferable skills through necessity}

\footnotetext{
21 ibid, p. 24

${ }^{22}$ ibid p.54. Krippendorf explains that "most content analyses involving patterns tend to be qualitative and based on small data sets" for practical reasons (see p57).

${ }^{23}$ Krippendorf states at p.62 "The frequency with which a symbol, idea, reference or topic occurs in a stream of messages is taken to indicate the importance of, attention to, or emphasis on that symbol, idea reference or topic in the messages."

${ }^{24}$ Krippendorf provides an example drawn from I. Pool, Symbols of Democracy (Stanford University Press, 1952) that symbols of democracy occur most frequently where democratic processes are under threat.

Hence in this context "symbols of democracy... represent something other than the degree to which democracy is accepted." p.66

${ }^{25}$ Leicester Award for Employability, supra n 11, pp.1-2
} 
As demonstrated in the table below (figure 2), by far the most commonly reported area of development among our student participants related to transferable skills, such as team work, leadership, communication and presentation skills. Of these, presentation skills ${ }^{26}$ was most frequently and commonly welcomed and acknowledged by participants as being developed through their involvement in the project, with 20 of the 25 making reference to it. Next to this, students identified communication skills as an area where they had most improved, both in terms of being able to confidently and effectively communicate to one another in the lead up to their school visit, and in the course of communicating complex legal information to children in a way that they would understand.

Figure 2

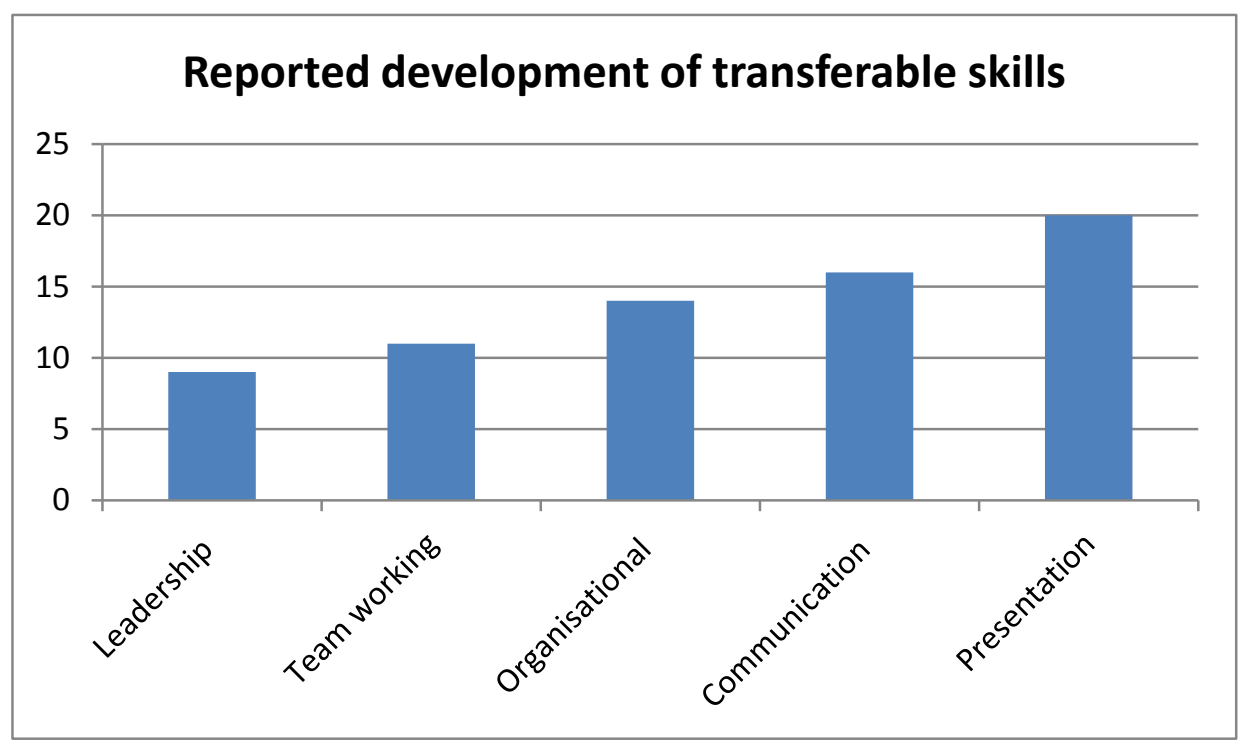

Rigg reports that communication skills are consistently ranked highly by graduate employers and observes: "Given the importance attached to communication skills by employers and students alike, it is surprising that assessment in law is still

\footnotetext{
${ }^{26}$ Also referred to in terms of 'performing' by some (9 out of 20$)$.
} 
overwhelmingly in form of written exams and assignment" ${ }^{27}$ and he suggest that the inclusion of oral assessment skills in student assessments could lead students to place greater emphasis upon developing them. Certainly it is possible that within this project, the requirement for students to make a presentation as part of their assessment, as well as the presentation of information within the classroom setting, served to give prominence to the oral communication aspect of their development. However, the impact of the group work context needs also to be acknowledged here. As Berry observes "having to work with one another and without tutor input forces students to improve their interpersonal skills, including communication" ${ }^{28}$ and although the group work emphasis in the project created a number of challenges (as will be discussed further below), it certainly provided an environment whereby students' communication skills were developed through necessity. As one student reports "Working in a group is not easy... First of all we begun by discussing group rules and guidelines just so we could be in unison at all times. After an hour or so of battling it out we came to a common understanding and I feel in a way this helped us grow to know a little more about each other which in future will make our meetings go a little smoother."

Alongside the development of communication and presentation skills, students reported increased levels of confidence as a result of being involved in the various aspects of the project. For some, this increase in confidence was associated specifically with enhancing communication skills or overcoming a fear of public speaking. ${ }^{29}$ For example, one student states "One of the main areas of development throughout this process has been my confidence. The ability to communicate effectively and confidently is something that I aimed to improve from the beginning, and conveniently many opportunities cropped up in this project for me to put these skills to practice" and another explains "I was able to overcome my fear when it came to communicating my ideas to others effectively." Arguably then, working in an environment that 'forces' the

${ }^{27}$ D Rigg, 'Embedding employability in assessment: searching for the balance between academic learning and skills development in law: a case study', (2013) Law Teacher 47: 3, 404-420, at 408.

${ }^{28}$ E Berry, 'Group work and assessment - benefit or burden?' (2007) The Law Teacher, 41:1, 19-36, at 31

${ }^{29} 19$ of 25 students reported increased levels of confidence. 
development of certain skills can prompt the associated benefit of increased levels of confidence, both with specific regard to those skills and more generally.

Perhaps not surprisingly, other skills that students tended to report as being developed within this environment were team-working and organisational skills. Fewer students referred to leadership skills. However, those who did refer to leadership tended to do so in a markedly reflective manner. For example, one states "I am quite confident I normally lead groups as others generally do not step forward, however I feel it would be more beneficial to others to allow them to lead and help them if needed therefore allowing them to develop personally." Other comments reveal again the development of skills through necessity; "I think that although I am not necessarily the most natural leader, I need to be more assertive about making my opinion known to the group when it comes to making key decisions." "I realised that when we were thinking about how to address the children, I needed to take a leadership role, I haven't really done this before so it was a good time to help develop the skill." "Whilst working in the teams to produce teaching materials I have found it important to take on a leading role in order to maximise the progress of our group and keep on top of our deadlines."

\section{The weakest area: Legal research skills}

As explained earlier, the areas of law that were going to be covered by the groups were determined in the first student workshop. Thereafter groups were instructed to carry out independent research into their chosen area and to determine from here the contents of their workshop for school. At the close of the project, the submission of group materials formed part of the Leicester Award assessment and included the requirement to provide 'A brief explanation of the subject matter of the workshop and the sources that you have drawn on in researching this area of law (max. 250 words)'. This aspect of the group materials, together with the students' blogs and our own 
observations of the visits to school, provide the basis for assessing how far the project helped to develop students' legal research skills.

In their reflective blogs, only 6 of the 25 students made explicit reference to having carried out research and of these, 4 referred to researching the area of law that they were covering. None reported that involvement in the project had developed their legal research skills. Two of the six had focused on researching how best to engage with the school children, rather than their chosen legal topic. As stated earlier, students' comments were made in a context that encouraged a focus on employability skills, so it may be that the lack of comment on legal research skills reveals nothing more than students' perception that these were not the type of skill that they were expected to reflect and comment upon. If so, then this is unfortunate, as they are considered as essential skills by their future employers. ${ }^{30}$

Our reading of the students' group materials and our observation of their work in school reveal that of course each of the groups did carry out some legal research. However, their focus on identifying the relevant law applicable, tended to rely heavily on secondary sources: text books, first year lecture notes (where relevant) and internet searches'. ${ }^{31}$ In reflecting on their visits to school, many students reported that in planning their activities they had underestimated the extent of the children's knowledge and intellectual abilities, ${ }^{32}$ and this may explain their 'light touch' approach to legal

\footnotetext{
${ }^{30}$ J.Webb, J.Ching, P.Maharg and A.Sherr, Setting Standards: The Future of Legal Services Education and Training Regulation in England and Wales (Legal Education and Training Review, 2013) (LETR), paras 2.99 and 7.15

${ }^{31}$ For example one group stated: 'As we are law students who are in their $2^{\text {nd }}$ and $3^{\text {rd }}$ year of study, we had already studied this topic in detail during our $1^{\text {st }}$ year. This meant that we used our notes and textbooks as guidance and a reminder as to what this area of law entailed. Revision books were of particular use for it gave a simple overview of the topic which helped us to understand what key concept we needed to explain during the workshops. Therefore the sources we mainly used were materials we had from studying this topic in our $1^{\text {st }}$ year.'

${ }^{32}$ Students felt in some instances that the material prepared was too easy and they have reflected upon that: '[we] felt that activities (especially activity one) were too easy for them and did not provoke enough thought and questioning'; 'After doing the workshop in the school we found that the children were much more intelligent than we gave them credit for and knew a lot about the topic we were discussing'.
} 
research. However, there remains a concern that prior to visiting the school none of the groups felt prompted to pursue more sophisticated and critical questions that were closely relevant to their topics. So questions such as whether it is possible for a child to sue or be sued in negligence; what happens if there has been an abuse of a child's right; or how far obligations imposed by statute (e.g. Animal Welfare Act 2006) apply to children were not pursued. Researching the law equated to finding out 'what the law is' as opposed to entering into a more in depth investigation and critical analysis of relevant primary and secondary sources. This is a cause for concern, echoing those expressed elsewhere that independent legal research skills are not being "sufficiently developed"33 within the undergraduate law degree. However, it is also an issue that could be addressed with future participants through the provision of additional training and guidance.

\section{On Reflection}

Having considered the impact of the project on its participants, the answer to the question "is it worth it?" is "yes" but with some reservations. It is pleasing to note that students report increased levels of confidence as a result of being involved in the project and that they have been able to identify a number of transferable skills as being further developed. The role of group work proved to be of particular significance in prompting some of this development, especially with regard to oral communication. As stated earlier, the students' reported emphasis upon the development of presentation skills is welcome, and can perhaps be linked to the assessment of that skill within the project. However, it seemed too that students tended to perceive their role in the school workshops as presenters or, for some, performers, as opposed to facilitators, mentors or enablers. On observing their work in school, it was clear that all of the groups encouraged active participation from the children, but each group tended to

\footnotetext{
${ }^{33}$ LETR, supra. n 30 para.7.94 and recommendation 11. See also J Guth,and C Ashford 'The Legal Education and Training Review: regulating socio-legal and liberal legal education? (2014) The Law Teacher 48:1, 5-19 at 16.
} 
take full responsibility for imparting legal knowledge to the children, as opposed to encouraging its discovery by them. Arguably this aligns with the students' own experience of legal education, comprising mainly of 'formal, taught ${ }^{34}$ programmes of study, presented within the most common format of large group lectures, followed by small group discussions. ${ }^{35}$ As explained above, our expectations in terms of the level and depth of legal research to be undertaken by the groups were not met, and it is evident that clearer guidance and monitoring needed to have been given to students in this area. But on reflection, it is considered that the impact on the learning experience of students has been broadly positive; they felt that had developed their transferable skills and gained in confidence. Hence it is appropriate now to comment on some of the associated benefits and challenges of the project, before drawing conclusions as to its future viability.

\section{Students as Partners}

When framing the project in response to the HEA's 'students as partners ${ }^{\prime 36}$ thematic call, it was contemplated that this phrase would adequately describe the process through which students would be engaged in working alongside academics in extracurricular outreach activities. However, this proved to be an underestimate of the extent to which the project would create a genuine engagement between staff and students in pursuit of a common educational goal. ${ }^{37}$ This was prompted from the outset by the engagement of external experts to lead the semester 1 workshops. Staff

\footnotetext{
${ }^{34}$ Watson adopts this phrase to describe the 'narrower, more usual form' of taught programmes of study, as opposed to broader approach that take a more holistic, transformative approach'. See P Watson, 'Leading change in Legal Education: Interesting ideas for interesting times' (2012) 22 Legal Education Review 199, at 201-202.

${ }_{35}^{35}$ Rigg,, supra n 29, p. 408.

${ }^{36}$ According to the HEA, working in partnership with students is a sophisticated and effective way of developing students engagement and enhancing learning and teaching. Partnership with students is a central theme of the HEA's work and cuts across other of its key areas such as assessment, employability, flexible pedagogies and retention and success. Available at https://www.heacademy.ac.uk/workstreamsresearch/themes/students-partners (accessed 21March 2015)

${ }^{37}$ Healey et al observe that commonly now "students act as partners in many...important ways, including institutional governance, quality assurance activities, research strategies and policies, estates, community engagement and other extra-curricular activities." In M Healey, A Flint and K Harrington, Engagement through partnership: students as partners in learning and teaching in higher education (HEA, 2014) p.7
} 
and students were genuinely involved in learning together and this had a positively disruptive effect on the relationship, providing a welcome challenge to "the constraints of traditional hierarchical relationships" ${ }^{38}$ and serving to develop a "sense of community" that is reported as occurring elsewhere student/staff partnership activities. $^{39}$ Although the final aims of the project were clear, the intermediate steps were to be worked out collaboratively, with students taking a leading role in determining the content and delivery of their workshops, without intervention from us. Instead, students were encouraged to liaise directly with the school's head teacher to discuss or check ideas.

There were advantages and disadvantages to delegating this level of responsibility. Although students were offered the opportunity of rehearsing their workshop before their school visit, in practice none had time to do so. Our opportunities for providing constructive criticism were limited therefore to the few minutes between the first and second running of the workshops in school. Conversely, the level of trust required to allow this on our part, served to enhance the sense of community and collegiality that had been established earlier in the project. Similarly, out of six potential logos for the project, the logo that was chosen by a student vote was the one least liked by us (because it featured a gavel) but was nevertheless adopted out of respect for the genuine staff/student partnership that had been established.

In a recent report published by the HEA, it is claimed that although engaging students in University activity at various levels is now commonplace, "Engaging students and staff effectively as partners in learning and teaching is arguably one of the most important issues facing higher education in the $21^{\text {st }}$ century ${ }^{\prime 40}$ and our experience in this project

\footnotetext{
${ }^{38}$ ibid, p.20 referring to Gough, K., Morris, J. and Hession, A. 'Media industries beyond the curriculum: motivating blended professionalism for enhanced student engagement and employability’ in: Nygaard, C., Brand, S., Bartholomew, P. and Millard, L. (Eds) Student Engagement: Identity, Motivation and Community (Faringdon: Libri Publishing, 2013) pp. 165-84

39 ibid.

${ }^{40}$ Healey et al, supra n 37 , p.7
} 
has prompted us to think about ways in which this can be further developed, particularly in the area of legal research.

\section{Group work}

This is another aspect of the project that proved to have greater significance than we envisaged at the outset, not least in providing the vehicle through which transferable skills would be develop through necessity. Perhaps because it was obvious that working in groups was the only way in which the project could be realistically undertaken, we did not experience any of the 'usual' resistance to the notion of working in groups in the formative and practical stages of the project. ${ }^{41}$ However, at the final stage of the project, when groups submitted their materials for assessment, we encountered some complaints that some team members had contributed very little to the work and should not be allowed to 'freeload' from the work of others. ${ }^{42}$ These complaints tended to focus on absences from group meetings and a lack of contribution to the workshop materials, rather than attendance at the school, where we observed that all participants were actively involved. As has been done elsewhere, we dealt with 'free-loading' complaints via a contribution sheet that allowed team members to comment on their own or a group member's level of contribution and reserved the right to alter marks by plus or minus $5 .^{43}$ On reflection, we realise that an opportunity for groups to agree and set out their own group rules needed to have been included at an early stage in the project, to provide an opportunity for group members to voice and clarify their expectations.

\section{Future viability}

\footnotetext{
${ }^{41}$ Such resistance is quite common - see Berry, supra n.28, p.34.

${ }^{42}$ Complaints that are common with group work. See further S Clarke and M Blissenden, 'Assessing student group work: is there a right way to do it? The Law Teacher (2013) 47: 3, 368-381 and Berry, supra n 28.

${ }^{43}$ See for example Berry, supra n 28 at p.29. We are very grateful to our colleague, Barbara Bogusz, who provided us with guidance and materials for this aspect of the project. Barbara includes within her materials the requirement for groups to agree group rules from the outset.
} 
An important factor to consider when determining the future viability of this project is the significance of key individuals. The project was made possible through the partnership with the UOL's School of Law and St Peter's Primary Academy, whose head teacher is a UOL law graduate. The project lead and project co-ordinator are colleagues who share a broad view of legal education and a willingness to experiment with new ideas. Certainly key individuals and the relationships between them can be the drivers for change and development. However, in order to be sustainable, reliance cannot be placed upon them indefinitely. Hence it is concluded that the viability of this project depends to some extent upon the willingness of additional members of staff to contribute and commit to its future development.

Running the project outside of the curriculum gave rise to some significant administrative challenges; due particularly to the fact that extracurricular activities are not timetabled. The day and half day workshops took place on Saturdays in Semester 1, as it proved impossible to find any other times that could accommodate all participants. Having no access to the timetable also precluded holding more regular whole group meetings between the initial development stages and the workshops in school. Both students and staff found it challenging to meet the requirements of the project at the same time as carrying out their timetabled activities. In light of this, we conclude that developing this work as part of the curriculum is a prerequisite to meeting the aim of creating a sustainable model for use in the future.

Aside from the practical challenges involved in developing this project as an extracurricular activity, there exists in our view the potential for expanding and more strongly emphasising its research element, thus providing a much-needed space for the development of legal research skills within the undergraduate curriculum. Because of its associated benefits, the group work nature of the project would remain, but would 
be augmented by much clearer and closer monitoring and guidance on the nature and level of research that needs to be undertaken. 